\title{
Carrión en los tiempos de la COVID-19
}

\section{Carrion in the times of COVID-19}

\section{Señor Editor:}

Más de 235 años después de la muerte del mártir de la Medicina, Daniel Alcides Carrión, un 5 de octubre, la actual pandemia de la Covid-19 presenta muchas similitudes con el escenario en que nuestro héroe protagonizó su gesta, y es una fecha en que todos los médicos peruanos renovamos su compromiso con la Salud Pública y la Medicina.

Por ello, este 5 de octubre, Día de la Medicina Peruana, tiene un significado especial para nosotros los médicos, pues además de conmemorar el sacrificio del joven provinciano, natural de Cerro de Pasco, estudiante de medicina, hoy héroe y mártir, también lamentamos la inmolación de 193 médicos, ubicados en la primera línea de batalla contra esta nueva pandemia de la COVID-19.

La figura del mártir de la medicina peruana es siempre el gran ejemplo que nos guía y fortalece en la lucha contra la actual pandemia del nuevo coronavirus, no solo porque muchos galenos han ofrendado su vida velando por la salud de sus compatriotas, sino también porque es un constante desafío para la ciencia y la medicina tratar de conocer mejor esta nueva y terrible enfermedad, y su posible curación, en medio de la severa crisis económica, política y social que se vive hoy en día, tanto en el Perú como en muchas partes del mundo, tal como fue, salvando las distancias, en la época que le tocó vivir a Carrión y donde llevó a cabo el máximo sacrificio, en aras de desentrañar una misteriosa y letal dolencia.

Se observan muchas coincidencias al comparar lo vivido por Carrión y las circunstancias que hoy atravesamos con este nuevo virus pandémico, que ha causado al 30 de setiembre del 2020, más de 32 mil fallecidos en el país (1), en tanto que el número de contagiados a nivel mundial alcanza más de 33 millones de personas (2), y se vaticina una segunda ola de nuevos casos, tal como está ocurriendo en parte de Europa, Israel, Australia, etc.

El sacrificio de Carrión renueva su vigencia en estos tiempos de la Covid-19 y recuerda la situación del Perú en torno a la infausta Guerra del Pacífico, allá por 1879 , también en medio de una grave crisis social, política y económica (3); en dicha época, una nueva dolencia desconocida, denominada "Fiebre de la Oroya “, conmovía al Perú y a una parte de la comunidad médica peruana y mundial por su alta letalidad en la fase hemática que puede llegar al $90 \%$, además que se desconocía el origen microbiológico, el reservorio, el vector y menos todavía alguna terapia o remedio mágico que la pudiera curar (4).

Fue en medio de ese escenario en que Carrión, imbuido de un gran valor científico y espíritu solidario, se inoculó una muestra de un paciente afectado por una fase eruptiva denominada "verruga peruana", tratando de conocer el comportamiento clínico de esa nueva enfermedad que arrasaba y mataba a miles de trabajadores del futuro ferrocarril de Lima a la Oroya.

De manera similar, la Covid-19, a ocho meses de su aparición en el mundo, aún se desconoce su reservorio, no se tiene terapia curativa, ni vacuna alguna, y no sabemos de su comportamiento clínico epidemiológico, tan cambiante y duro.

Las grandes epidemias y pandemias son fenómenos cada día más frecuentes en todo el mundo, por ello siempre debemos analizar y recordar su

\footnotetext{
Facultad de Medicina, Universidad Peruana Cayetano Heredia. Lima, Perú

Colegio Médico del Perú. Lima, Perú.

Profesor Principal

Médico Infectólogo y Tropicalista;

Vicedecano Nacional
} 
comportamiento epidemiológico e histórico, ya que nos permiten reflexionar sobre el impacto que tienen en la salud, economía y la vida del planeta.

Cabe recordar que la última gran pandemia mundial fue la de influenza, que produjo más de 50 millones de muertes, tuvo grandes tres olas, la de 1919 produjo más muertes que la primera de 1918 (5).

Es importante destacar un hecho inédito en la medicina durante esta pandemia, y es que el personal de salud sea uno de los más seriamente afectados. Ellos son los grandes protagonistas para ayudar a detener y controlar la enfermedad, pero con el terrible saldo de 193 médicos fallecidos en todo el país, quienes son los nuevos héroes y mártires de la salud, que hoy acompañan a Carrión y tantos otros más que se inmolaron por la vida y la medicina en el mundo.

Hoy día existen más de 30 especies de Bartonella en el mundo, por eso se las considera una de las enfermedades zoonóticas; el reservorio de la enfermedad de Carrión es el humano, existen diversas terapias antibióticas para la fase aguda y eruptiva, pero hasta la fecha no tenemos vacuna alguna; si bien esta enfermedad está controlada hoy, pero debido al cambio climático y otros fenómenos ambientales siempre está latente su reemergencia $(6,7)$.

\section{Ciro Maguiña Vargas $\mathbf{s}^{1, \mathrm{a}, \mathrm{b} ; 2, \mathrm{c}}$}

\section{REFERENCIAS BIBLIOGRÁFICAS}

1. Ministerio de Salud. Sala Situacional COVID-19 Perú. Lima: Ministerio de Salud; 2020. (Citado el 30 de setiembre del 2020); Disponible en: https:// covid19.minsa.gob.pe/sala_situacional.asp

2. Johns Hopkins University. COVID-19 Dashboard by the Center for Systems Science and Engineering (CSSE). Baltimore: Johns Hopkins University; 2020. (Citado el 30 de setiembre del 2020) Disponible en: https://www.arcgis.com/apps/opsdashboard/ index.html\#/bda7594740fd40299423467b48e9ecf6

3. Macera D. La reconstrucción despues de la guerra. Lima: Diario El Comercio; 234 de abril del 2020. (Citado el 30 de setiembre del 2020) Disponible en: https://elcomercio.pe/opinion/columnistas/lareconstruccion-despues-de-la-guerra-por-diegomacera-noticia/

4. Maguiña C, Garcia PJ, Gotuzzo E, et al. Bartonellosis (Carrion's Disease) in the modern era. Clin Inf Dis 2001; 33:772-779.

5. Centros para el Control y la Prevención de Enfermedades. Historia de la pandemia de influenza de 1918. Washington DC: Centros para el Control y la Prevención de Enfermedades; 2018. (Citado el 30 de setiembre del 2020) Disponible en: https://espanol.cdc.gov/flu/pandemicresources/1918-commemoration/1918-pandemichistory.htm

6. Maguiña C, Ugarte C, Breña $P$, Ordaya E, Ventosilla P, Huarcaya E, Henriquez C. Actualización de la enfermedad de Carrión. Rev. Med. Hered; 2008 ene.mar; 19(1):36-41.

7. Maguiña C; Pachas P. Experiencias en la prevención y control de la Enfermedad de Carrión en el Perú. Rev Perú Med Exp Salud Pública Perú. 2014; 31(2):34851.

Recibido: 30/09/2020 